\section{Suicide by prisoners}

\author{
National clinical survey
}

JENNY SHAW, DENISE BAKER, ISABELLE M. HUNT, ANNE MOLONEY and LOUIS APPLEBY

\begin{abstract}
Background The number of suicides in prison has increased over recent years.

This is the first study to describe the clinical care of a national sample of prison suicides.
\end{abstract}

Aims To describe the clinical and social circumstances of self-inflicted deaths among prisoners.

Method A national clinical survey based on a 2-year sample of self-inflicted deaths in prisoners. Detailed clinical and social information was collected from prison governors and prison health care staff.

Results There were 172 self-inflicted deaths: 85 (49\%; 95\% Cl 42-57) were of prisoners on remand; 55 (32\%; $95 \% \mathrm{Cl}$

\section{5-39) occurred within 7 days of} reception into prison. The commonest method was hanging or self-strangulation (92\%; 95\% Cl 88-96). A total of 110 (72\%; $95 \% \mathrm{Cl} 65-79)$ had a history of mental disorder. The commonest primary diagnosis was drug dependence (39, 27\%; 95\% Cl 20-35). Eighty-nine (57\%; 95\% Cl 49-64) had symptoms suggestive of mental disorder at reception into prison.

Conclusions Suicide prevention measures should be concentrated in the period immediately following reception into prison. Because hanging is the commonest method of suicide, removal of potential ligature points from cells should be a priority.

Declaration of interest None.
The number of suicides in prison in England and Wales has increased in recent years (Her Majesty's Chief Inspector of Prisons, 1999; Hancock, 2002; Royal College of Psychiatrists, 2002). Prisoners are predominantly socially disadvantaged young men, a group in whom the suicide rate has increased in society generally (Department of Health, 2002). The prevalence of important risk factors for suicide, such as mental illness and drug and alcohol misuse, is higher in prison than in the community (Jenkins \& Meltzer, 1995; Singleton et al, 1998; Meltzer et al, 1999). The prison environment itself may increase suicide risk (Liebling, 1994). Previous studies have described the characteristics of self-inflicted deaths in prison (Fruhwald et al, 2002; Wobeser et al, 2002; Coffey et al, 2003), but this paper describes the first national study of self-inflicted deaths in prison in which detailed clinical data have been collected on individual cases. Its aims were to describe the timing and methods of prison suicide and the clinical and social antecedents of suicide by prisoners.

\section{METHOD}

\section{Prison procedures}

Prisons contain those serving sentences, awaiting trial (remand prisoners) and awaiting sentencing. Prisoners are transferred from court to prison and between prisons under the supervision of the Prison Escort Custody Service. The first point of contact between prisoner and prison staff is reception, when all prisoners are interviewed, their personal details recorded and a health proforma completed. Prisoners believed to be at risk of self-harm or suicide may have an F2052SH form 'opened'. The $\mathrm{F} 2052 \mathrm{SH}$ is designed to enable prison staff to keep a concise record of the prisoner's needs, risk, problems and care. Staff in contact with a prisoner on whom an
F2052SH is 'open' make regular notes about him/her and if the prisoner moves to another wing or prison, the document accompanies him/her. Prisoners thought to be particularly at risk may be located in the health care in-patient centre, if available, or in specialised cells in which a gate replaces the usual metal door, providing an opportunity for observation and closer interaction with staff. Prisoners with mental health problems may be referred to resident or visiting mental health professionals or to in-patient mental health units in National Health Service (NHS) hospitals.

\section{Prison statistics}

The ratio of men to women in the prison population is 18:1 (Home Office, 2002), $16 \%$ of prisoners are aged 21 years or under (Home Office, 2002) and $19 \%$ are remand prisoners (Home Office, 2002).

\section{National clinical survey}

Information on all self-inflicted deaths in prisons in England and Wales between 1 January 1999 and 31 December 2000 was forwarded by Her Majesty's Prison Service Safer Custody Group. These deaths were those considered to be suicides or probable suicides by the Safer Custody Group, regardless of a subsequent inquest verdict. It is conventional for studies of suicide to include probable suicides in which another verdict was reached, usually an open verdict. In this study we also included verdicts of misadventure and accidental death if the death occurred by hanging.

Data collection was based on methods used by the National Confidential Inquiry into Suicide and Homicide by People with Mental Illness, to investigate suicides by people under mental health care (Appleby et al, 2001). For each self-inflicted death the prison medical officer and prison governor were asked to complete questionnaires in consultation with other members of staff who knew the prisoner. The questionnaires covered:
(a) demographic details;
(b) details of the suicide;
(c) events leading to suicide;
(d) clinical history;
(e) history of contact with NHS mental health services;
(f) contact with prison health care and non-health care staff; 
(g) assessment of risk of suicide at last contact with health care staff; and

(h) respondents' views on prevention.

The prison medical officers' questionnaire asked whether the prisoner had seen a psychiatrist and, if so, information on mental health was obtained from the psychiatrist, who was asked to complete a similar questionnaire.

\section{Statistical analysis}

Data were analysed using the Statistical Package for the Social Sciences (SPSS), Version 10. Estimates are presented as proportions, with $95 \%$ confidence intervals given for the main variables. If an item of information was not known for a case, the case was removed from the analysis of that item; the denominator in all estimates is, therefore, the number of valid cases for each item.

\section{RESULTS}

\section{Sample}

There were 172 self-inflicted deaths in prison in England and Wales over the 2year period 1999-2000. This included 99 cases $(58 \%)$ in which the coroner recorded a verdict of suicide, 25 open verdicts $(14 \%), 17$ cases $(10 \%)$ of misadventure and 18 accidental deaths $(10 \%)$. At the time of data collection the coroner's verdict was unavailable for 13 cases $(8 \%)$. This sample of self-inflicted deaths will be referred to as suicides for the remainder of this paper.

Completed questionnaires were returned by prison medical officers in 157 cases (91\% response rate), by prison governors in 163 cases (95\% response rate) and by psychiatrists in 29 cases (69\% response rate).

\section{Rates of suicide}

The average total prison population for 1999 was 64771 and for 2000 it was 64602 . The average rate of suicide per 100000 population per year for 1999 and 2000 was 133; the age-standardised rate in the general population in 1999-2001 was 9.4 per 100000 . The rate for women was 184 per 100000 population per year, and for men it was 129 per 100000 population per year; the age-standardised rates in the general population in 1999-2001 were 4.5 per 100000 in women and 14.5 per 100000 in men. In young age groups, the male suicide rates exceeded 20 per 100000 in the same 3-year period.

\section{Location}

The 172 suicides occurred in 65 prisons, with 12 prisons ( 10 for adult males and 2 young offenders institutions) experiencing five or more deaths. Five suicides occurred under the Prison Escort Custody Service. Fifty-eight $(34 \%)$ suicides were in shared cells but in 30 the cell mate was absent at the time of death.

\section{Timing}

A total of 55 (32\%; 95\% CI 25-39) suicides occurred within 7 days of reception into prison, $19(11 \%)$ of them within $24 \mathrm{~h}$. Early suicides were more common in drugdependent prisoners: 22 (59\%) died within 7 days of reception.

\section{Method}

The commonest method of suicide was hanging or self-strangulation (159 cases, 92\%; 95\% CI 88-96). Thirteen individuals $(8 \%)$ used a method other than hanging.

\section{Social and criminological characteristics}

Table 1 shows the social and criminological characteristics of all prison suicides. The ratio of men to women overall was 12:1 but in those under 21 years of age it was $6: 1$. Thirty-one $(18 \%)$ were aged 21 years or under.

Forty-one $(26 \%$; $95 \%$ CI $19-33)$ were charged with or convicted of a violent offence. Eighty-five $(49 \%$; $95 \%$ CI $42-57)$ were on remand. The suicide rate per 100000 population per year for remand

Table I Social and criminological characteristics of self-inflicted deaths in prison $(n=172)$

\begin{tabular}{|c|c|c|c|}
\hline & $n$ & $\%$ & $95 \% \mathrm{Cl}$ \\
\hline Age (years): median (range) & 28 & $(17-75)$ & \\
\hline Male & 159 & 92 & $88-96$ \\
\hline \multicolumn{4}{|l|}{ Ethnicity } \\
\hline White & 153 & 89 & 84-94 \\
\hline Black (African and Caribbean) & 13 & 8 & $4-12$ \\
\hline Indian subcontinent & 3 & 2 & $0-4$ \\
\hline Other & 3 & 2 & $0-4$ \\
\hline \multicolumn{4}{|l|}{ Marital status } \\
\hline Single & 122 & 76 & $70-83$ \\
\hline Married or cohabiting & 22 & 14 & $8-19$ \\
\hline Divorced or separated & 14 & 9 & $4-13$ \\
\hline Living alone & 10 & 14 & $6-22$ \\
\hline Homeless & 9 & 13 & $5-20$ \\
\hline \multicolumn{4}{|l|}{ Offence } \\
\hline Murder/manslaughter & II & 6 & $2-10$ \\
\hline Attempted murder & 6 & 4 & $0-6$ \\
\hline Other violent offences & 24 & 16 & $11-22$ \\
\hline Sexual offences & 15 & 9 & $5-13$ \\
\hline Arson/criminal damage & 12 & 7 & $3-11$ \\
\hline Theft/burglary/robbery & 74 & 43 & $35-50$ \\
\hline Other & 30 & 15 & $|0-2|$ \\
\hline \multicolumn{4}{|l|}{ Status } \\
\hline Remand & 85 & 49 & $42-57$ \\
\hline Convicted but unsentenced & 20 & 12 & $7-16$ \\
\hline Convicted & 67 & 39 & $32-46$ \\
\hline
\end{tabular}


prisoners was 339 (see above for general population rates).

\section{Clinical characteristics}

Table 2 shows the main clinical characteristics of the 157 suicides on whom questionnaires were returned by prison medical officers. Information from psychiatrists is also included where applicable.

A total of $110(72 \%$; 95\% CI 6579) prisoners had at least one known psychiatric diagnosis. The commonest primary diagnosis was drug dependence (39, $27 \%$; $95 \%$ CI $20-35)$. Ten $(6 \%$; $95 \%$ CI 3-11) had a diagnosis of schizophrenia and 26 (18\%; $95 \%$ CI $12-25)$ had a diagnosis of affective disorder. The most frequent secondary diagnosis was drug dependence. A history of drug misuse, alcohol misuse, previous self-harm and violence were common.

\section{Reception screening}

In 89 (57\%; 95\% CI 49-64) cases, symptoms of mental disorder were detected at reception to prison, most commonly intoxication or withdrawal from drugs or alcohol $(43,27 \%)$, anxiety $(27,17 \%)$, thoughts of self-harm or suicide (25, $16 \%)$, or depression $(25,16 \%)$. Forty-six prisoners $(30 \%$; 95\% CI 23-37) were known to have had contact with mental health services prior to their prison term. Twenty-four (15\%) had no contact with health care staff after reception.

\section{Information transfer}

At reception, 110 (70\%) prisoners reported having a general practitioner, but he/she was contacted for information in only 18 cases $(16 \%)$ and in only $10(9 \%)$ was this within 1 week of reception. Of the 46 prisoners $(29 \%)$ with a history of contact with NHS mental health services, an attempt was made to gather information from the service in only 17 cases $(37 \%)$.

\section{In-patient and post-discharge suicides}

Twenty-seven (17\%; 95\% CI 11-22) suicides occurred in prison health care inpatient centres. We received detailed clinical information on 26 of these. Twenty-one $(81 \%)$ had been admitted because of mental health problems, most often (10 cases) an act of deliberate selfharm or the expression of suicidal ideas. Fifteen $(60 \%)$ died within 7 days of

Table 2 Clinical characteristics of self-inflicted deaths in prison $(n=157)$

\begin{tabular}{|c|c|c|c|}
\hline & $n$ & $\%$ & $95 \% \mathrm{Cl}$ \\
\hline \multicolumn{4}{|l|}{ Clinical features } \\
\hline \multicolumn{4}{|l|}{ Primary diagnosis } \\
\hline Schizophrenia & 10 & 7 & $3-11$ \\
\hline Affective disorder (bipolar and depression) & 26 & 18 & $12-25$ \\
\hline Neurotic disorder & 6 & 5 & $0-8$ \\
\hline Alcohol dependence & 5 & 4 & $0-7$ \\
\hline Drug dependence & 39 & 27 & $20-35$ \\
\hline Personality disorder & 15 & II & $6-16$ \\
\hline Other & 10 & 7 & $3-11$ \\
\hline Any secondary diagnosis & 46 & 32 & $24-39$ \\
\hline \multicolumn{4}{|l|}{ Duration of history } \\
\hline$<12$ months & 25 & 16 & $10-22$ \\
\hline $\mathrm{I}-5$ years & 28 & 18 & $12-24$ \\
\hline$>5$ years & 29 & 18 & $12-25$ \\
\hline Previous admission to NHS psychiatric hospital & 19 & 14 & $8-20$ \\
\hline Previous contact with NHS services & 46 & 30 & $23-37$ \\
\hline \multicolumn{4}{|l|}{ Behavioural features } \\
\hline History of self-harm & 78 & 53 & $45-61$ \\
\hline History of violence & 47 & 35 & $27-43$ \\
\hline History of alcohol misuse & 46 & 31 & $23-38$ \\
\hline History of drug misuse & 95 & 62 & $54-70$ \\
\hline \multicolumn{4}{|l|}{ Prison mental health } \\
\hline Symptoms at reception & 89 & 57 & $50-65$ \\
\hline Referred to a psychiatrist & 50 & 32 & $25-40$ \\
\hline Transferred to NHS hospital while a prisoner & 4 & 3 & $0-5$ \\
\hline On an open F2052SH at the time of death & 38 & 24 & $|8-3|$ \\
\hline Died in prison hospital in-patient care & 27 & 17 & $11-22$ \\
\hline Died after discharge from prison hospital in-patient care & 45 & 29 & $22-36$ \\
\hline \multicolumn{4}{|l|}{ Contact with prison health care staff } \\
\hline Last contact within $24 \mathrm{~h}$ of death & 84 & 56 & $48-64$ \\
\hline Symptoms at last contact & 55 & 37 & $29-45$ \\
\hline Estimate of risk low or none at last contact & $|4|$ & 93 & 89-97 \\
\hline Suicide thought to be preventable & 22 & 15 & $9-21$ \\
\hline
\end{tabular}

NHS, National Health Service.

admission to in-patient care. Eleven $(42 \%)$ were under medium or high levels of observation at the time of death.

A further 45 (29\%; 95\% CI 22-36) had previous admissions to prison health care in-patient centres. Nineteen $(12 \%)$ had had multiple admissions during this prison term. In $30(67 \%)$ the final admission had lasted less than 7 days. Sixteen $(36 \%)$ died within 7 days of discharge from prison health care and in $12(27 \%)$ no follow-up appointment with a health care professional was made. The remainder had a post-discharge follow-up appointment with health care staff, visiting psychiatrists or both, but in $10(30 \%)$ of these the suicide occurred before the appointment took place.

\section{F2052SH forms (for prisoners regarded at risk)}

Eighty-five $(51 \%)$ prisoners had an open F2052SH form at some time during their sentence. Thirty-eight $(24 \%$; $95 \%$ CI 18 31) prisoners had an open F2052SH form at the time of death.

\section{Perceived risk at final contact}

In total, $141(90 \%)$ of this sample could be considered at high risk of suicide because of previous history of contact with NHS 
mental health services (46), a lifetime history of mental disorder (110), current symptoms (89), current treatment (53) or a history of drug misuse (95), alcohol misuse (46) or self-harm (78). However, most suicides were thought to be at no or low risk at their final contact with services.

\section{Prevention}

Prison health care teams regarded only 22 $(15 \%$; 95\% CI 9-21) suicides as preventable. However, more often they suggested factors that could have made suicide less likely, including: closer supervision (69, $46 \%$ ), better staff training in risk assessment $(39,26 \%)$, placement in a cell with another prisoner or a listener $(39$, $26 \%)$, increased staff numbers $(34,23 \%)$, better prisoner support and clinical management $(33,22 \%)$ and better communication between staff $(31,21 \%)$. Interestingly, staff made no mention of limiting access to means/ligature points as a way of preventing suicide in individual cases. Deaths in prisoners on an open F2052SH form or in health care in-patient centres, in convicted prisoners and in those under 21 years of age were more likely to be seen as preventable.

\section{DISCUSSION}

This study describes all self-inflicted deaths within the prison system in England and Wales within a 2-year period. We found that one-third of suicides occurred within 7 days of reception into prison. The commonest method of suicide was by hanging. The rates of mental disorder in the sample were high and nearly one-third had had previous contact with NHS mental health services. The transfer of information from general practitioners and mental health services into prison was uncommon. Few prisoners were reported to be suffering from depression, in keeping with previous findings on young suicides (Appleby et al, 1999). However, it could be because depression is frequently overlooked in prisoners (Shaw et al, 1997). In most prisoners who committed suicide there was evidence of suicide risk at the time of reception screening. At final contact, however, perceived risk of suicide was low. This could be explained in part by the methodology, that is, those completing questionnaires were aware of the outcome (suicide). However, it may also indicate problems with suicide risk assessment, in particular

\section{CLINICAL IMPLICATIONS}

One-third of suicides occurred within a week of entry into prison; II\% occurred within $24 \mathrm{~h}$.

Suicide is most commonly by hanging, using bedclothes and window bars.

- The rate of pre-existing mental disorder, particularly drug dependence, is high but information exchange between the National Health Service and prisons is poor.

\section{LIMITATIONS}

This is an uncontrolled study of suicide and no aetiological conclusions can be drawn.

- Clinicians and other prison staff completing questionnaires may have been biased by awareness of outcome (suicide).

Recommendations have not been subject to clinical trials.

JENNY SHAW, MRCPsych, DENISE BAKER, MA, ISABELLE M. HUNT, BA, ANNE MOLONEY, MSc, LOUIS APPLEBY, FRCPsych, National Confidential Inquiry into Suicide and Homicide by People with Menta Illness, Centre for Suicide Prevention, University of Manchester, Manchester

Correspondence: Jenny Shaw, National Confidential Enquiry into Suicide and Homicide by People with Mental IIIness, Centre for Suicide Prevention, Williamson Building, University of Manchester, Manchester MI3 9PL,UK. E-mail: Jennifer.J.Shaw@man.ac.uk

(First received 10 April 2003, final revision 15 October 2003, accepted 3 November 2003)

distinguishing acute from longer-term risk. Suicide rates were many times the all-ages rates in the general population and were particularly high in women and in remand prisoners.

\section{Methodological issues}

This study is primarily a clinical survey carried out on prisoners judged to have died by suicide. This gives rise to four important limitations of the findings.

First, without control subjects, aetiological conclusions cannot be drawn. Many of the risk factors for self-harm and suicide are common to prisoners in general. However, the findings show the characteristics of people in whom suicide must be prevented if prison suicide rates are to be reduced. Because many of these characteristics are risk factors for suicide in the general population, it seems likely that they were also part of the causal pathways that led to suicide. We are about to begin a case-control study that will provide data to allow the relative importance of individual and servicelevel risk factors to be determined.
Second, clinicians and other prison personnel completing questionnaires may have been biased by their awareness of outcome, and this may have affected, in particular, their reporting of estimates of risk at last contact. However, most items in the questionnaire were factual and should not have been affected by any bias in the respondents.

Third, the recommendations on suicide prevention (below) have not been subject to major clinical trials. Even so, we believe that they represent good practice on suicide prevention and are also likely to benefit non-suicidal prisoners.

Fourth, suicide rates were not standardised by age and are not strictly comparable with the general population figures presented here. However, the rates among prisoners are substantially higher than rates in the comparable age and gender group in the general population.

\section{Implications for suicide prevention in prisons}

In a high-risk population, identifying those at highest and most immediate risk is 
difficult. These results suggest the need to recognise the fluctuating and long-term nature of suicide risk in prisoners, to monitor risk continually and to link supervision and other preventive measures to regular assessment. A system of care planning of this kind should now be considered as an alternative to current prison procedures based on the F2052SH form.

The findings in this paper also identify the days following reception into prison as the period when suicide prevention measures are most needed, and hanging as the main suicide method to prevent.

Some measures that should be taken are listed below.

(a) For prisoners thought to be at risk following reception, initial supervision should take place in dedicated reception wings.

(b) Cells without window bars should be available for prisoners at high risk.

(c) Prisons should provide bed linen that cannot be used in hanging or selfstrangulation.

(d) Information sharing should be routine; when screening reveals a history of mental health service contact, relevant information should be obtained within $24 \mathrm{~h}$. (e) Detoxification facilities should be available for prisoners with a history of alcohol or drug misuse or dependence.

(f) When prisoners are discharged from prison in-patient facilities, they should be followed up within 7 days.

(g) Staff, including escort staff, should receive regular training on the recognition, assessment and management of suicide risk; this should emphasise the risk among remand prisoners.

A full list of recommendations is presented in the Safer Prisons report (Shaw et al, 2003).

\section{REFERENCES}

Appleby, L., Cooper, J., Amos, T., et al (1999) Psychological autopsy study of suicides by people aged under 35. British journal of Psychiatry, 175, 168-174.

Appleby, L., Shaw, J., Sherratt, J., et al (200I) Safety First. Five-Year Report of the National Confidential Inquiry into Suicide and Homicide by People with Mental Illness. London: Department of Health.

Coffey, C., Veit, F., Wolfe, R., et al (2003) Mortality in young offenders: retrospective cohort study. BMJ, 326, 1064.

Department of Health (2002) National Suicide Prevention Strategy for England. London: Stationery Office.

Fruhwald, S., Frottier, P., Benda, N., et al (2002) Psychosocial characteristics of jail and prison suicide victims. Wiener Klinische Wochenschrift, I14, 691-696.
Hancock, N. (2002) Suicide trends. Safer Custody News, 19, I-8.

Her Majesty's Chief Inspector of Prisons (1999) Suicide is Everyone's Concern. A Thematic Review. London: Home Office.

Home Office (2002) Prison Statistics, England and Wales. London: Research, Development and Statistics Department.

Jenkins, R. \& Meltzer, H. (1995) The national survey of psychiatric morbidity in Great Britain. Social Psychiatry and Psychiatric Epidemiology, 30, I-4.

Liebling, A. (1994) Suicide amongst women prisoners. Howard Journal, 33, I-9.

Meltzer, J., Jenkins, R., Singleton, J., et al (1999) NonFatal Suicidal Behaviour Among Prisoners. London: Office for National Statistics.

Royal College of Psychiatrists (2002) Suicide in Prisons (CR99). London: Royal College of Psychiatrists.

Shaw, J. (1997) The prevalence of mental disorder in the court population. PhDThesis, University of Manchester.

Shaw, J., Appleby, L. \& Baker, D. (2003) Safer Prisons - A National Study of Prison Suicides 1999-2000 by the National Confidential Inquiry into Suicides and Homicides by People with Mental Illness. London: Department of Health

Singleton, N., Meltzer, H., Gatward, R., et al (1998) Psychiatric Morbidity among Prisoners in England and Wales. London: HMSO.

Wobeser, W. L., Datema, J., Bechard, B., et al (2002) Causes of death among people in custody in Ontario, 1990-1999. Canadian Medical Association Journal, 167, 1109-1113. 